\title{
Static versus Dynamic DEA in Federal Higher Education Institutions - IFES
}

Edward Martins Costa* Francisco de Sousa Ramos** Hermíno Ramos de Souza***

\begin{abstract}
The present study aims to analyze intertemporal changes in productivity at Federal Higher Education Institutions (IFES) from 2004 to 2008. It examines efficient frontiers from each year using slacks-based (SBM-DEA) and dynamic slacks-based measures (DSBM) for data envelopment analysis (DEA). The total set of IFES was divided into two subsets (group A and group B) in order to minimize heterogeneity in the sector. Estimation results show that static frontiers for both groups underestimate the institution efficiency during the study period, indicating that intertemporal frontiers are more accurate when calculating efficiency since they consider a variable link between the inputs and outputs intertemporally.
\end{abstract}

Keywords: Efficiency. DEA. Productivity.

JEL Classification: C67; I23.

\section{Introduction}

Two of the most common methods for measuring efficiency are the statistic (or econometric) and the mathematical (or deterministic) approach, both of which are distinctive.

According to Forsund, Lovell and Schmidt (1980), econometrics presupposes that efficiency follows a specific distribution. Nevertheless, there are some disadvantages to using this approach. A misspecification error may occur, often caused by the functional form of the production function. Furthermore, the measurement of efficiency in which there are multiple inputs and outputs is not easily applied in a parametric model.

In accordance with Sengupta (1999), the non-statistical approach is often nonparametric, using linear programming methods to calculate the efficient frontier based on inputs and outputs, thereby avoiding misspecification errors. Further-

* Doutor em Economia pela Universidade Federal de Pernambuco (UFPE). Professor dos Departamentos de Economia e de Finanças da Universidade Federal do Ceará (UFC). E-mail: edwardcosta@ufc.br

** Doutor em Economia pela Université Catholique de Louvain. Professor do Departamento de Economia da UFPE. E-mail: ramosfs@gmail.com. O autor agradece o apoio da Bolsa de Produtividade do Cnpq.

*** $\quad$ Doutor em Economia pela UFPE. Professor do Departamento de Economia da UFPE. E-mail: herminio.ramos@gmail.com 
more, the use of programming methods is appropriate in situations with multiple inputs and outputs. There are two basic disadvantages to this approach. As per Geva May (2001), it does not provide estimates or significance tests of parameters and the efficiency frontier can only be defined by a small sample.

Selection of the method should consider its application in the area of research used and primarily, consider the composition of the inputs and outputs that form part of the production process. Thus, measuring efficiency in cases of multiple inputs and outputs is better achieved by nonparametric methods and Data Envelopment Analysis (DEA) is the most applicable for studies of technical or allocative efficiency.

Traditional DEA models treat the efficiency of resources (inputs and outputs) related to making decisions in DMUs (decision-making units) with cross-sectional data. In other words, the analysis is performed in only one time period, hampering the measurement of productivity changes when there is more than one time period.

Window analysis and the Malmquist index were the first methods used to verify productivity change over time. However, these models do not capture the effect of carry-over activities (links) between two consecutive time periods. These models have inputs and outputs for each period, but linking activities between the periods are not computed explicitly. The dynamic DEA model proposed by Fare, Rolf and Grosskopf (Intertemporal Production Frontiers: with Dynamic DEA, 1996) is the first system that formally addresses the activities in different interconnected time periods.

The subject of how public resources should be allocated in higher education has directed substantial research at measuring the efficiency of public IFES. Over the years, a number of studies have aimed to measure efficiency and rank public IFES according to their degree of efficiency. Moreover, every country has its own funding and resource allocation structure, which serves as a basis for estimating efficiency in the higher education sector.

The structure of higher education in Brazil is relatively new, and in the past years it has changed a lot. Some changes in Legislation, increase of private investment, academic expansion, and some families claiming for better education are some of the changes that have been happening in the last decades. In view of the benefits originated from these changes, academic education has been motivating more investments and politics related to improvements in this sector.

The Federal Higher Education Institutions in Brazil (IFES) are funded mainly by the federal government through linkage of some duties foreseen in Article 212 of the 1988 Brazilian Constitution. In order to have its academic, research and extension activities, institutions get allocation from Union resources done by the Secretary of Higher Education, of the Ministry of Education (SESu/MEC) through a head office of allocation that tries to give some privilege to the IFES efficiency. 
IFES are distinguished by their size, being named big, medium and small. So, the analysis of the universities' size is important, because it gives a notion of possible homogeneity or heterogeneity in the total set of Brazilian IFES. Some indicators corroborate the identification of the IFES sizes, highlighting among them: registered students, budgetary distribution, professors, and researches.

In the field of education, DEA has been successfully applied to measure the relative efficiency of public schools and universities. DEA methodology enables the use of variables that are not only monetary; it considers several criteria in determining the efficiency index, and - in addition to being a relative efficiency measurement - is suitable for use in investigations in the area of education, allowing performance assessment of these institutions.

Belloni (2001), in his Doctorate thesis, evaluated the performance of productive efficiency in 33 Brazilian federal universities, using the study in DEA methodology. The author verified that the propriety of constant returns to scale did not apply in the case of public federal universities. So, his estimations were done according to DEA-BCC model, with returns variable to scale.

Oliveira and Turrioni (2005) evaluated the relative efficiency of Federal Higher Education Institutions in Brazil (IFES). The inputs and outputs were built using indicators of the Federal Court of Accounts (TCU). The DEA-CCR model considered the constant returns to scale. Nineteen federal institutions of higher education were evaluated, from which five were considered technically inefficient. Comparing these results to the ones obtained by Belloni (2001), it was noted that the ones from Oliveira and Turrioni (2005) pointed to the opposite direction, maybe because they used a model with constant income to scale.

Costa, Ramos and Souza (2011) analyzed the efficiency of IFES educational product from 2004 to 2008 through Dynamic DEA model. In the study, the educational inputs and outputs were chosen in a way to obtain the educational frontier that best represented the academic formation of these institutions. The model used for analysis took into consideration only the Dynamic frontier. However, a comparison between dynamic and static frontier from each year is necessary, in order to know the distinction between estimation results, as well as the advantages and disadvantages among the models.

As such, it is important to compare the static and dynamic frontiers of federal higher education in order to better understand the dynamic of the efficiency process of Federal Higher Education Institutions (IFES).

In this respect, the present study aims to analyze the static and intertemporal frontiers of Brazilian Federal Higher Education Institutions (IFES) using slacks-based (SBM-DEA) and dynamic DEA (DSBM), and compare the two methods based on the resulting frontiers. In addition to this introduction, the second chapter addresses economic efficiency, the DEA method for static efficiency and DSBM for 
the dynamic efficiency model. The third section describes the model for measuring efficiency and obtaining data. The fourth portion presents the results and discussion and the final section details the conclusions.

\section{Methodology and Database}

Efficiency is related to how resources are used and allocated. Initial research on efficiency began in the 50's with Debreu (1951), Koopmans (1951), Shephard (1953) and Farrell (1957). Johnes and Johnes (2004) considered the approach used by Farrell (1957) to measure efficiency appropriate.

Farrell (1957) presented two structures for gauging efficiency. The first is called the input-oriented approach, which seeks to answer the following question: how much can the organization proportionally reduce its inputs without altering the number of outputs produced? The second measure is output-oriented and is concerned with responding to the question: for a specific set of inputs, how much can organizational output be increased?

In accordance with Farrell (1957), the empirical frontier of production is an envelopment line that contains the set of production possibilities for a given level of input usage. A production plan found on this frontier is deemed "efficient", while those inside it belong to the "inefficient" subset.

Souza and Ramos (1997) state that efficiency can be dichotomized into two aspects: (i) the physical relationships between outputs and inputs (productive efficiency), and (ii) the efficiency of prices in "optimal" allocation of resources (allocative efficiency). To a certain extent, this distinction is in fact an artificial measure when considering production decisions in conjunction: the choices that affect allocative efficiency may have technical implications and vice-versa. Nevertheless, it is known that these decisions can be empirically separated.

\subsection{Data Envelopment Analysis (DEA)}

The Data Envelopment Analysis method (DEA) was developed by Charnes, Cooper and Rhodes (1978) and generalizes the measures of Dantzing (1951) and Farrel (1957). It seeks to measure the productive efficiency of production units with multiple inputs and outputs to obtain an indicator that satisfies Koopman's efficiency criterion.

DEA estimation is nonparametric and measures the efficiency of the decision-making units (DMUs) studied, comparing them amongst themselves and obtaining an indicator of relative efficiency. This methodology uses the DMUs as the best practices observed and applies them in the construction of an empirical production frontier, called the efficient frontier. 


\subsubsection{Static DEA (SBM)}

The slacks-based DEA model (SBM) was introduced by Tone (1997) and Tone and Tsutsui (2001) and consists of the following two presuppositions:

i) Measurement is constant in relation to the unit of measurement for each input and output item.

ii) Measurement is monotonically decreasing at each input and output slack.

To assess the efficiency of a DMU using the DEA-SBM model, the following fractionated problem of (PL) is defined in $\lambda, s^{-}, s^{+}$.

$$
\begin{aligned}
& \lambda, s^{-}, s^{+} \rho=\frac{1-\frac{1}{m} \sum_{i=1}^{m} s_{i}^{-} / x_{i o}}{1-\frac{1}{s} \sum_{i=1}^{s} s_{i}^{+} / \mathrm{y}_{r o}} \\
& \text { subject to } \quad x_{o}=\mathrm{X} \lambda+s^{-} \\
& y_{o}=Y \lambda-s^{+} \\
& \lambda \geq 0, s^{-} \geq 0, s^{+} \geq 0
\end{aligned}
$$

The model assumes that $X \geq 0$.If $x_{i o}=0$ the expression $s_{i}^{-} / x_{i o}$ is excluded. On the other hand, if $y_{i o} \leq 0$, the positive number will be very small, hence the expression $s_{i}^{+} / y_{r o}$ plays a detrimental role.

The $\rho$ value of the objective function satisfies the first assumption, given that the numerator and denominator are measured in the same unit for each expression of this function. Furthermore, the value of the objective function declines after increases in $s_{i}^{-}$and $s_{i}^{+}$, with other constant terms maintained; this is due to the second assumption. In addition, $0 \leq \rho \leq 1$.

The SMB model can be defined by input and output-oriented measures, as well as non-oriented structures. The present study discusses only the output-oriented approach, defined by the following equation:

[Output-oriented structure]

$$
\begin{aligned}
(S B M-O) \rho_{o}^{*}=\min _{\lambda, s^{+}} \frac{1}{1+\frac{1}{s} \sum_{i=1}^{s} s_{i}^{+} / \mathrm{y}_{r o}} \\
\text { subject } b \quad x_{o}=\mathrm{X} \lambda \\
y_{o}=Y \lambda-s^{+} \\
\lambda \geq 0, s^{+} \geq 0
\end{aligned}
$$




\subsubsection{Dynamic DEA}

Based on the model proposed by Fare and Grosskopf (1996), Tone and Tsutsui (2010) used carry-over variables in the dynamic DEA model to estimate the production frontier over several time periods. Additionally, frontier estimation is performed via a non-radial model, that is, a slacks-based measure known as dynamic SBM (DSBM), whose structure is shown in the figure below.

Figure 1 - Dynamic DEA Structure

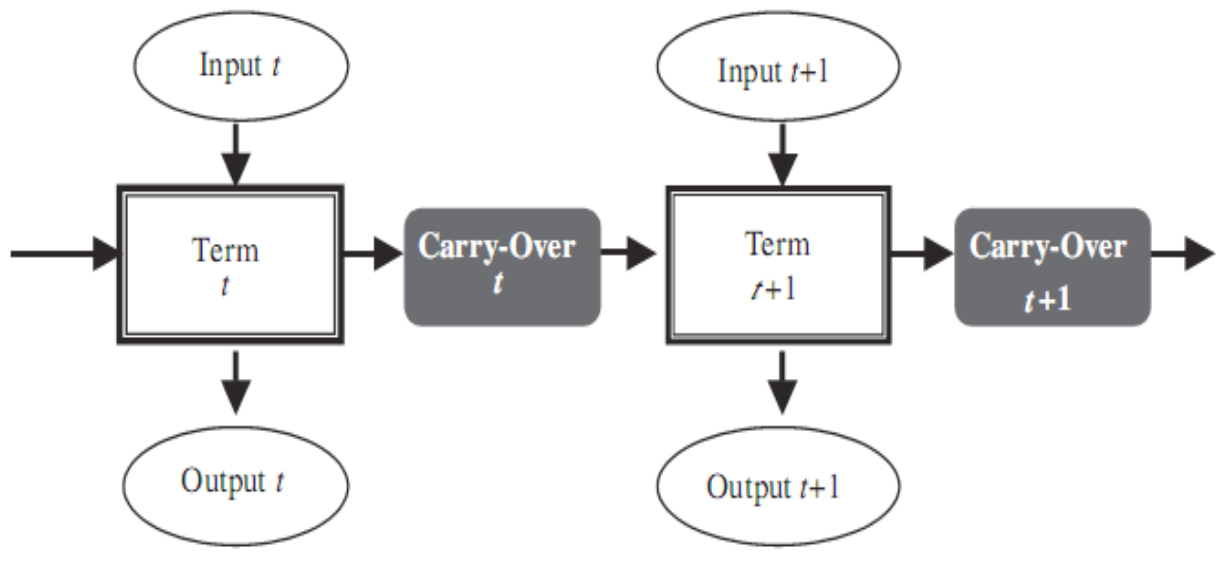

Source: Dynamic DEA: A slacks-based measure approach.

The element that distinguishes dynamic DEA from other types of DEA is the existence of a transition that links the periods over time. The carry-overs, known as links, fall into the following four categories:

Desirable (good) - good links are treated as outputs and the value of the link is restricted to not less than that observed. The comparative scarcity of links in this category is considered inefficiency; for example, profit.

Undesirable (bad) - bad links are treated as inputs. Their value is limited and cannot be greater than that observed. A comparative excess of links in this class is deemed inefficient; for instance, deficits and defaults.

Discretionary (free) - this link can be freely manipulated by the DMU and its value can be increased or decreased from the observed value. Deviation in relation to the real value is not directly reflected in efficiency assessment, but the condition of continuity between the two time periods explained in the following period exerts an indirect effect on the efficiency score.

Non-discretionary (fixed) - in this case, the link is beyond the control of the DMU and its value is fixed at an observed level. This link also indirectly affects the efficiency score through the condition of continuity between the two time periods. 


\section{Production possibility set}

For $n$ DMUs $(j=1, \ldots, n)$ over $T$ time periods $(t=1, \ldots, T)$, where each period has $m$ inputs $(i=1, \ldots, m), p$ fixed inputs $(i=1, \ldots, p), s$ outputs $(i=1, \ldots, s)$ and $r$ fixed outputs $(i=1, \ldots, r)$. In addition, the discretionary inputs $x_{i j t}(i=1, \ldots m)$ , non-discretionary inputs $x_{i j t}^{f x e d}(i=1, \ldots p)$, discretionary outputs $y_{i j t}(i=1, \ldots s)$ and non-discretionary outputs $y_{i j t}^{\text {fixed }}(i=1, \ldots r)$ represent, respectively, the DMU values $j$ and the time period $t$. The carry-overs are symbolized in four categories $\left(z^{\text {good }}\right.$, $\left.z^{\text {free }}, z^{\text {bad }}, z^{\text {fixed }}\right)$. In order to identify the time period ( $t$ ), DMU (j) and the item (i), we apply the notation $z_{i t}^{\text {free }}$ : free $(i=1, \ldots$, free; $j=1, \ldots n ; t=1, \ldots, T)$, which denotes all the free link values observed up to the time period $T$.

Thus, the production possibility set $\left\{x_{i t}\right\},\left\{x_{i t}^{\text {fixed }}\right\},\left\{\mathrm{y}_{i t}\right\},\left\{\mathrm{y}_{i t}^{\text {fixed }}\right\},\left\{\mathrm{z}_{i t}^{\text {good }}\right\}$, $\left\{\mathrm{z}_{i t}^{\text {bad }}\right\},\left\{\mathrm{z}_{i t}^{\text {free }}\right\},\left\{\mathrm{z}_{i t}^{\text {fixed }}\right\}$ is defined by:

$$
\begin{array}{rlrl}
x_{i t} & \geq \sum_{j=1}^{n} x_{i j t} \lambda_{j}^{t}, & (i=1, \ldots, m ; t=1, \ldots, T) \\
x_{i t}^{\text {fixed }}=\sum_{j=1}^{n} x_{i j t}^{\text {fixed }} \lambda_{j}^{t}, & (i=1, \ldots, p ; t=1, \ldots, T) \\
\mathrm{y}_{i t} \leq \sum_{j=1}^{n} y_{i j t} \lambda_{j}^{t}, & (i=1, \ldots, s ; t=1, \ldots, T) \\
\mathrm{y}_{i t}^{\text {fixo }}=\sum_{j=1}^{n} y_{i j t}^{\text {fixed }} \lambda_{j}^{t}, & (i=1, \ldots, r ; t=1, \ldots, T) \\
\mathrm{z}_{i t}^{\text {good }} \leq \sum_{j=1}^{n} z_{i j t}^{\text {good }} \lambda_{j}^{t}, & (i=1, \ldots, n g o o d ; t=1, \ldots, T) \\
\mathrm{z}_{i t}^{\text {bad }} \geq \sum_{j=1}^{n} z_{i j t}^{\text {bad }} \lambda_{j}^{t}, & (i=1, \ldots, n b a d ;=1, \ldots, T) \\
\mathrm{z}_{i t}^{\text {free }}: \text { free }, & (i=1, \ldots, n f r e e ; t=1, \ldots, T) \\
\mathrm{z}_{i t}^{\text {fix }} \geq \sum_{j=1}^{n} z_{i j t}^{\text {fixed }} \lambda_{j}^{t}, & (i=1, \ldots, n f i x e d ; t=1, \ldots, T) \\
\lambda_{j}^{t} \geq 0 & (j=1, \ldots, n ; t=1, \ldots, T)
\end{array}
$$




$$
\sum_{j=1}^{n} \lambda_{j}^{t}=1, \quad(t=1, \ldots, T)
$$

Where $\lambda_{j}^{t} \in \mathfrak{R}^{n}(t=1, \ldots, T)$ is the intensity vector for time period $t$, and ngood, nfree, nfixed are the number of good, free and fixed links, respectively. The ${ }^{1 \text { st }}$ restriction corresponds to the hypothesis of variable returns to scale. In the absence of this restriction, the model falls within constant returns to scale. To the right of the above equations the variables assume positive values, while on the left are variables corresponding to the intensity vector.

The continuity of carry-over links between time period $t$ and $t+1$ is guaranteed by the following condition:

$$
\sum_{j=1}^{n} z_{i j t}^{\alpha} \lambda_{j}^{t}=\sum_{j=1}^{n} z_{i j t}^{\alpha} \lambda_{j}^{t+1} \quad(\forall i ; t=1, \ldots, T-1)
$$

Where the symbol $\alpha$ is standard for good, bad, free and fixed links. This restriction is fundamental to the dynamic model since it connects the activities between time period $t$ and $t+1$. Using these equations for production, $D M U_{o}(o=1, \ldots, n)$ can be expressed as follows:

$$
\begin{array}{ll}
x_{i o t}=\sum_{j=1}^{n} x_{i j t} \lambda_{j}^{t}+s_{i t}^{-}, & (i=1, \ldots, m ; t=1, \ldots, T) \\
x_{\text {iot }}^{\text {fixed }}=\sum_{j=1}^{n} x_{i j t}^{\text {fixed }} \lambda_{j}^{t}, & (i=1, \ldots, m ; t=1, \ldots, T) \\
y_{\text {iot }} \leq \sum_{j=1}^{n} y_{i j t} \lambda_{j}^{t}-s_{i t}^{+}, & (i=1, \ldots, s ; t=1, \ldots, T) \\
y_{\text {iot }}^{\text {fixed }}=\sum_{j=1}^{n} x_{i j t}^{\text {fixed }} \lambda_{j}^{t}, & (i=1, \ldots, r ; t=1, \ldots, T) \\
z_{\text {iot }}^{\text {good }}=\sum_{j=1}^{n} z_{i j t}^{\text {good }} \lambda_{j}^{t}-s_{i t}^{\text {good }}, & (i=1, \ldots, \text { ngood } ; t=1, \ldots, T) \\
z_{\text {iot }}^{\text {bad }}=\sum_{j=1}^{n} z_{i j t}^{\text {bad }} \lambda_{j}^{t}+s_{i t}^{\text {bad }}, & (i=1, \ldots, \text { nbad } ;=1, \ldots, T)
\end{array}
$$




$$
\begin{array}{ll}
z_{\text {iot }}^{\text {free }}=\sum_{j=1}^{n} z_{i j t}^{\text {free }} \lambda_{j}^{t}+s_{i t}^{\text {free }}, & (i=1, \ldots, \text { nfree; } t=1, \ldots, T) \\
z_{\text {iot }}^{\text {fixed }}=\sum_{j=1}^{n} z_{i j t}^{\text {fixed }} \lambda_{j}^{t}, & (i=1, \ldots, n f i x ; t=1, \ldots, T) \\
\sum_{j=1}^{n} \lambda_{j}^{t}=1, & (t=1, \ldots, T)
\end{array}
$$$$
\lambda_{j}^{t} \geq 0, s_{i t}^{-} \geq 0, s_{i t}^{+} \geq 0, s_{i t}^{\text {good }} \geq 0, s_{i t}^{\text {bad }} \geq 0 \text { e } s_{i t}^{\text {free }}: \text { free }(\forall i, t)
$$

Where $s_{i t}^{-}, s_{i t}^{+}, s_{i t}^{\text {good }}, s_{i t}^{\text {bad }}$ and $s_{i t}^{\text {free }}$ are the slack variables denoting, respectively, input excess, output shortfall, link shortfall, link excess and link deviation.

\section{Objective Function and Efficiency}

The evaluation of overall efficiency of a $D M U_{o}(o=1, \ldots, n)$ with $\left\{\lambda^{t}\right\}$, $\left\{s_{t}^{-}\right\},\left\{s_{t}^{+}\right\},\left\{s_{t}^{\text {good }}\right\},\left\{s_{t}^{\text {bad }}\right\},\left\{s_{t}^{\text {free }}\right\}$ is performed via input, output and non-oriented structures. In light of the definition of the research model, we will only address the output-oriented measure. The overall output-oriented $\tau_{o}^{*}$ with a good link is given by:

$$
\frac{1}{\tau_{o}^{*}}=\max \frac{1}{T} \sum_{t=1}^{T} w^{t}\left[1+\frac{1}{s+n g o o d}\left(\sum_{i=1}^{s} w_{i}^{+} s_{i}^{+}+\sum_{i=1}^{\text {goood }} \frac{s_{t}^{\text {good }}}{z_{\text {iot }}^{\text {good }}}\right)\right]
$$

Subject to equations (4) and (5), where $w_{i}^{+}$is the weight for output $i$ and satisfies the condition:

$$
\sum_{i=1}^{s} w_{i}^{+}=s
$$

This objective function is an extension of the output-oriented SBM model and deals with output inefficiencies including the link (good), which functions as an essential goal in assessment. Undesirable inefficiency links are also considered within the objective function, as occurs with output inefficiencies. However, undesirable links are not outputs; they only carry out the function of connecting the two consecutive time periods, as denoted in equation (4). In equation (6), each period within the brackets represents the efficiency of period $t$ measured by the slacks relative to the outputs and link, and is equivalent to the unit when these equal zero. Furthermore, they are constant units and their value is greater than or equal to 1 . Thus, 
the right side of equation (6) is the weighted average of efficiency gains over time, which must be more than or equal to 1 . Therefore, provided that overall efficiency is defined, by reciprocity the overall efficiency of the output is between 0 and 1 .

Using the optimal solution $\left\{\lambda^{*}\right\},\left\{s_{t}^{-*}\right\},\left\{s_{t}^{+^{*}}\right\},\left\{s_{t}^{\text {good }}\right\},\left\{s_{t}^{\text {bad }}\right\},\left\{s_{t}^{\text {free }}\right\}$, output-oriented dynamic efficiency $\tau_{o t}^{*}$ is defined as:

$$
\tau_{o t}^{*}=\frac{1}{1+\frac{1}{s+n g o o d}\left(\sum_{i=1}^{s} w_{i}^{+} s_{i o t}^{+^{*}}+\sum_{i=1}^{\text {ngood }} \frac{s_{i o t}^{\text {good }}}{z_{\text {iot }}^{\text {good }}}\right)},(t=1, \ldots, T)
$$

As such, output-oriented overall efficiency during period $\left(\tau_{o t}^{*}\right)$ is a harmonic mean of efficiencies for the periods $\left(\tau_{o t}\right)$, demonstrated below:

$$
\frac{1}{\tau_{o t}^{*}}=\frac{1}{T} \sum_{t=1}^{T} \frac{w^{t}}{\tau_{o t}^{*}}
$$

\subsection{Model for Efficiency Measurement and Data Base}

The concept of efficiency is related to the use and allocation of resources. So, in order to obtain reliable estimations in the efficiency calculus it is necessary to use indicators that represent in a consistent way the characteristics of the educational production function.

From main outputs and inputs used in several works in the last decades, the set of efficiency indicators shown, and considering the reality of the federal system of higher education in Brazil, the outputs and inputs to be used in order to measure the efficiency of Federal Higher Education Institutions in Brazil (IFES) in this work are:

\section{Output}

The educational outputs might be defined as function of services offered by Institutions of Higher Education in Brazil (IES). So, for this study, the following variables were defined as output:

Graduated students/registered students (TSG).

Concept of Coordination for Enhancement of Higher Education Personnel (CAPES)/MEC for Post-Graduation programs. 


\section{Graduated students/registered students (TSG)}

The reason graduated students/registered students is defined by the Court of Accounts (TCU) ${ }^{1}$ as the rate of success in undergraduate courses (TSG). Its calculus is done with the following formula:

$$
T S G=\frac{\text { Number of graduated students }\left(N_{D I}\right)}{\text { Total amount of new students }}
$$

The number of graduated students is $\left(N_{D I}\right)$ considered the total of students who graduated in both semesters of the school year. On the other hand, the total amount of new students is according to the year or semester they started the course. $^{2}$

TSG aims to represent a product in the educational productive process that contemplates the question of IFES academic performance. However, it is known that there are some methodological considerations to be done, such as: the possible mobility of students in the institution (through changes in the courses inside the institution) or to other institutions, and the possibility of existing graduated students registered for many years.

Lastly, it is possible to think that TSG in its calculus might not capture the quality of the graduated student. However, despite this limitation, among other, TSG is considered in this work an important product for the efficiency calculus in the educational productive sector, because it considers that the "number of graduated students" index incorporates a good measure of academic quality for IFES.

\section{CAPES/MEC concept for Post-Graduation}

According to TCU (2004), the calculus of CAPES/MEC concept for Post-Graduation is done through arithmetic mean of concepts obtained by all strict sensus Post-Graduation programs. This product is considered very important in the efficiency calculus of educational productive sector, because it gets IFES education and research committal level.

Input

The educational inputs might be defined as those variables that make the services offered by Institutions of Higher Education in Brazil (IES) possible. Thus, for this research, the following variables were defined as input:

Current cost/equivalent student.

Full time student/equivalent professor.

Full time student/equivalent employees.

TCU Decision N. 408/2002.

For more details, see: Orientation for Calculus of Management Indicators - TCU. March, 2004. 
Qualification of teaching staff index.

\section{Current cost/equivalent student}

It basically measures the current cost of student for each IFES. Its calculus is done by the sum of expenses from the university in question, divided by the number of equivalent students.

Full time student/equivalent professor

It captures the ability to help students done by the teaching staff. Its calculus is obtained through the reason between total of equivalent students by total of professors.

Full time student/equivalent employees

It determines the capacity to serve students done by all attendants. Its calculus is done by the reason of total equivalent students by the total of attendants.

Qualification of teaching staff index

The qualification of teaching staff index - IQCD measures the level of graduation of the teaching staff. Its calculus is done through a mathematic formula that tries to determine the contribution of permanent and temporary professors of a higher education institution.

The variable carry-over chosen to do the linkage between periods is the total of equivalent students. ${ }^{3}$ The choice of this variable is due to the fact that it is part of a resource allocation model from SESu/MEC for IFES, corresponding to an important variable in the allocation of resources for institutions.

From outputs, inputs and the carry-over variable shown, it is determined the model that reflects the productive efficiency of activities, teaching quality, research and management indicators.

Model

Inputs:

Current cost/equivalent student.

Full time student/equivalent professor.

Full time student/equivalent employees

Qualification of teaching staff index.

3 According to MEC, the indicator equivalent student determines the total of registered students in certain IFES from a mathematic formula that compares the students from differentiated courses. Thus, it is possible to compare the total amount of students in all courses and all IFES in study. 
Outputs:

Graduated students/registered students (TSG).

Concept of Coordination for Enhancement of Higher Education Personnel (CAPES)/MEC for Post-Graduation programs.

\subsubsection{Data obtainment}

The variables used in this work were obtained, mainly, with the following agencies:

Ministry of Education (MEC), in the website: <http:/www.mec.gov.br $>$. National Institute of Educational Studies and Research (INEP), in the website: <http://www.inep.gov.br>.

Coordination for Enhancement of Higher Education Personnel (CAPES), in the website: <http://www.capes.gov.br >.

After DMUs are defined and the model is pointed, the period to analyze the efficiency measurement is determined. The criterion for such determination was found based on data availability of indicators used in the research. So, the period analyzed will be from 2004 to 2008 .

\section{Result Analysis}

Federal Higher Education Institutions are highly homogeneous, making it difficult to estimate the production frontier. Therefore, in an attempt to achieve consistent results, we sought to minimize the heterogeneous nature of the sector by considering the reality of each institution, which were divided into two groups; Group A (considered large IFES) and Group B (deemed small IFES): in the first group are institutions with a greater role in graduate studies and research, while the second group contains institutions with little or no role in these areas.

\subsection{IFES Group A}

The table below depicts the mean total technical efficiency (Overall Score) for both estimations. 
Table 1 - FIHE Group A: Total efficiency of the static and dynamic models (dynamic ranking)

\begin{tabular}{|c|c|c|c|c|}
\hline \multirow{2}{*}{ IFES } & \multicolumn{2}{|c|}{ Dynamic Frontier } & \multicolumn{2}{|c|}{ Static Frontier } \\
\hline & Rank & Overall Score & Rank & Overall Score \\
\hline FURG & 23 & 0.87 & 23 & 0.87 \\
\hline UFAL & 25 & 0.86 & 27 & 0.84 \\
\hline UFAM & 1 & 1 & 1 & 1 \\
\hline UFBA & 1 & 1 & 1 & 1 \\
\hline UFC & 21 & 0.88 & 21 & 0.89 \\
\hline UFCG & 1 & 1 & 16 & 0.94 \\
\hline UFES & 22 & 0.88 & 25 & 0.85 \\
\hline UFF & 1 & 1 & 16 & 0.96 \\
\hline UFG & 27 & 0.85 & 24 & 0.87 \\
\hline UFLA & 1 & 1 & 18 & 0.92 \\
\hline UFMG & 1 & 1 & 1 & 1 \\
\hline UFMT & 1 & 1 & 1 & 1 \\
\hline UFPA & 1 & 1 & 1 & 1 \\
\hline UFPB & 1 & 1 & 1 & 1 \\
\hline UFPE & 20 & 0.91 & 19 & 0.91 \\
\hline UFPEL & 1 & 1 & 1 & 1 \\
\hline UFPR & 26 & 0.85 & 28 & 0.81 \\
\hline UFRGS & 1 & 1 & 1 & 1 \\
\hline UFRJ & 1 & 1 & 1 & 1 \\
\hline UFRN & 19 & 0.92 & 20 & 0.89 \\
\hline UFRPE & 1 & 1 & 1 & 1 \\
\hline UFSC & 24 & 0.86 & 22 & 0.88 \\
\hline UFSCAR & 1 & 1 & 1 & 1 \\
\hline UFSM & 1 & 1 & 1 & 1 \\
\hline UFU & 1 & 1 & 1 & 1 \\
\hline UFV & 1 & 1 & 1 & 1 \\
\hline UNB & 28 & 0.84 & 26 & 0.85 \\
\hline UNIFESP & 1 & 1 & 1 & 1 \\
\hline
\end{tabular}

The two frontiers are relatively similar; however, the introduction of the carry-over variable means that the dynamic frontier contains more IFES on the frontier, despite score variations for IFES below it.

When the position of each IFES on the two efficient frontiers is analyzed vis-à-vis, the overalls scores of dynamic DEA for most IFES are higher when compared to those obtained by static DEA. Moreover, in the shift from dynamic to static, the UFCG, UFF and UFLA moved below the frontier. Nevertheless, their overall scores were $0.94,0.96$ and 0.92 respectively, indicating that although they formed part of the inefficient set in the static model, they were not far from the frontier. On the other hand, UFRN, UFPE, UFC, UFES, FURG, UFSC, UFAL, UFRPR, UFG and $\mathrm{UNB}$ were located below the efficient frontier for the overall scores of static and 
dynamic efficient frontier estimation, accounting for approximately $100 \%$ of the inefficient set for the dynamic model and $77 \%$ of inefficient institutions in the static model.

Figure 1 - IFES from Group A: Total Dynamic versus Total Static Efficiency

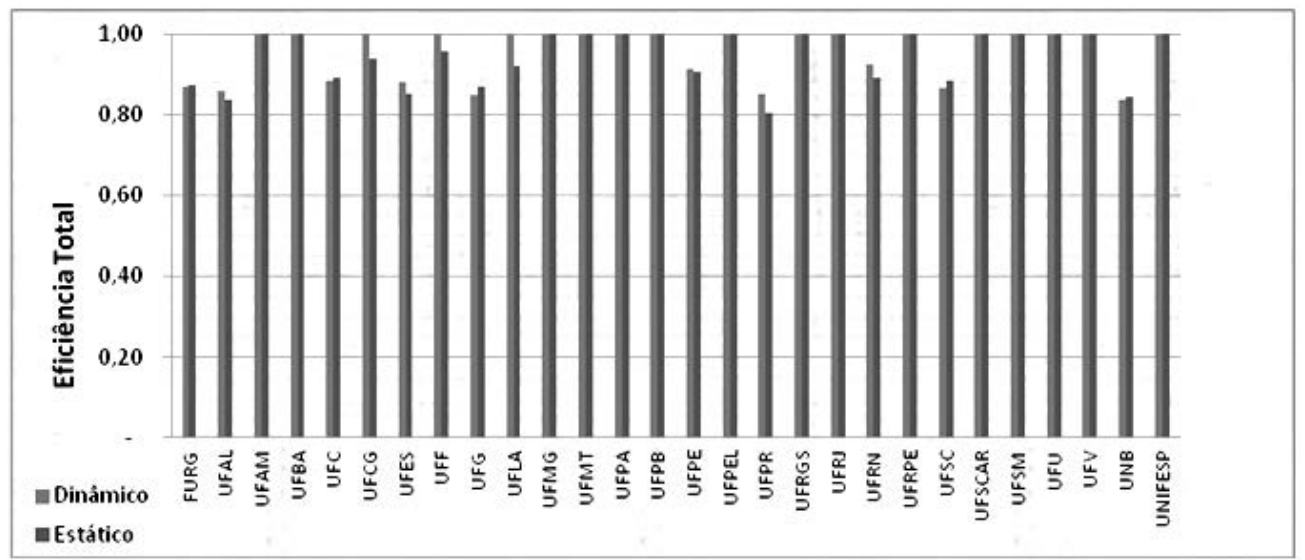

Source: Research estimates compiled by the author.

Finally, the above graph shows the vis-à-vis position of each IFES in the estimation models, indicating a fall or rise in total efficiency. In addition to IFES that moved away from the efficient frontier, when changing from the dynamic to static model, the institutions UFRN, UFES, UFSC, UFAL, and UNB exhibited an increase in the degree of inefficiency, while IFES UFPE, UFC, FURG and UFG showed a decline in inefficiency.

\subsection{IFES Group B}

The table below shows the mean total technical efficiency (overall score) for both estimations. 
Table 2 - IFES Group B: Total efficiency of the static and dynamic models (dynamic ranking)

\begin{tabular}{|c|c|c|c|c|}
\hline \multirow{2}{*}{ IFES } & \multicolumn{2}{|c|}{ Dynamic Frontier } & \multicolumn{2}{|c|}{ Static Frontier } \\
\hline & Rank & Overall Score & Rank & Overall Score \\
\hline UFAC & 1 & 1 & 12 & 0.97 \\
\hline UFCSPA & 1 & 1 & 1 & 1 \\
\hline UFERSA & 1 & 1 & 17 & 0.9 \\
\hline UFJF & 1 & 1 & 11 & 0.98 \\
\hline UFMA & 17 & 0.99 & 9 & 0.99 \\
\hline UFMS & 1 & 1 & 20 & 0.8 \\
\hline UFOP & 18 & 0.95 & 15 & 0.92 \\
\hline UFPI & 1 & 1 & 16 & 0.91 \\
\hline UFRA & 1 & 1 & 10 & 0.98 \\
\hline UFRR & 1 & 1 & 13 & 0.96 \\
\hline UFRRJ & 1 & 1 & 14 & 0.94 \\
\hline UFSE & 1 & 1 & 1 & 1 \\
\hline UFSJ & 20 & 0.84 & 19 & 0.82 \\
\hline UFT & 1 & 1 & 1 & 1 \\
\hline UFTM & 1 & 1 & 1 & 1 \\
\hline UFVJM & 1 & 1 & 1 & 1 \\
\hline UNIFAL & 1 & 1 & 1 & 1 \\
\hline UNIFAP & 1 & 1 & 1 & 1 \\
\hline UNIFEI & 19 & 0.9 & 18 & 0.85 \\
\hline UNIR & 21 & 0.8 & 21 & 0.76 \\
\hline UNIRIO & 1 & 1 & 1 & 1 \\
\hline
\end{tabular}

Source: Research estimates compiled by the author.

For this group, the two technical efficient frontiers exhibited differences; consequently, the efficient frontier of the static overall score is situated at a lower level for all IFES whe compared with the dynamic overal score frontier. As a result, when the IFES frontiers of group A and B are compared, the latter shows a more significant difference between the frontiers with the introduction of the carry-over link.

When analyzing the position of each IFES on both efficient frontiers vis-à-vis, UFAC, UFERSA, UFJF, UFMS, UFPI, UFRA, UFRR and UFRRJ moved below the frontier when the model changed from the static to the dynamic, becoming part of the inefficient set, even though their overall scores were $0.97,0.90,0.98,0.80$, $0.91,0.98,0.96$ and 0.92 , respectively.

We therefore concluded that although these IFES were considered inefficient in the static model, they were not far from the frontier, with the exception of UFERSA and UFMS. By contrast, UFMA, UFOP, UNIFEI, UFSJ, and UNIR were below 
the efficient frontier for overall scores in both the static and dynamic estimates, corresponding to $100 \%$ of inefficient institutions in the dynamic model and $38 \%$ of the inefficient set in the static model.

Finally, the graph below illustrates the vis-à-vis position of each IFES in the estimation models, indicating an increase or decline in total efficiency. In addition to the IFES that left the efficient frontier, UFOP, UNIFEI, UFSJ, and UNIR, demonstrated greater inefficiency when shifting from the dynamic to static model, with UFMA showing the same level of inefficiency.

Figure 2 - IFES Group B: Total Dynamic versus Total Static Efficiency

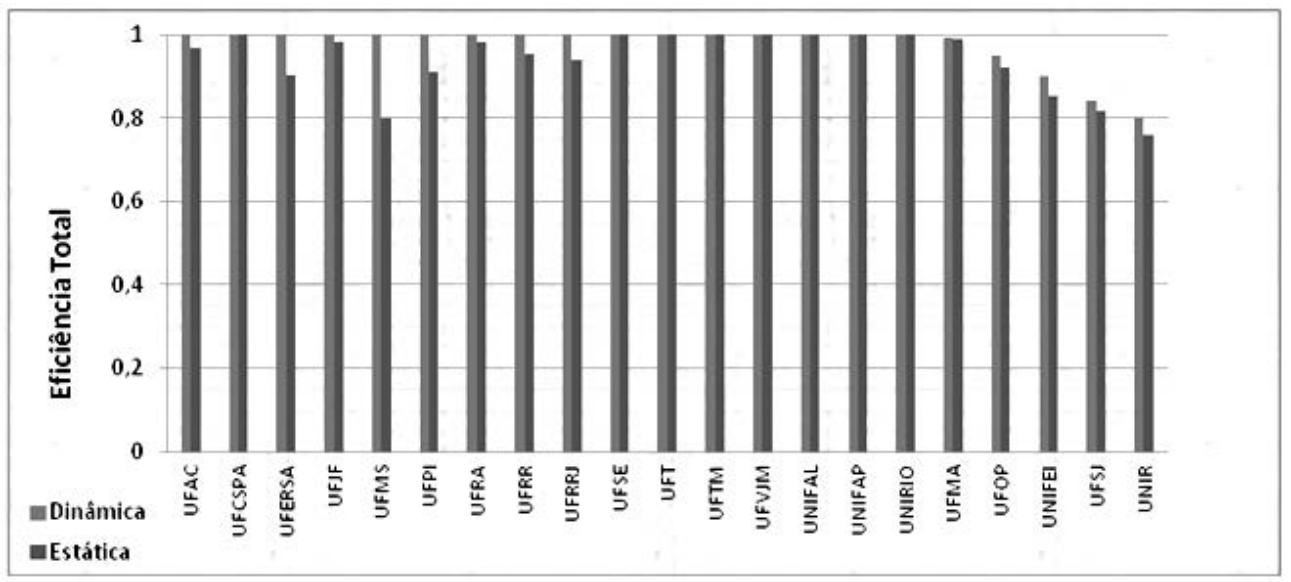

Source: Research estimates compiled by the author.

The results of both groups show that dynamic frontier is situated in a superior level when compared to static frontier. The advantage in obtaining an intertemporal frontier is inclusion, in efficiency scores, of inputs and outputs behaviors during the period of time analyzed, through the use of a connection variable generating a stronger efficiency frontier. This hardiness appears due to the connection variable in the model (total of equivalent students). This indicator in the matrix of resources allocation for IFES with the purpose of catching maintenance costs, in the rubrics referring to Other Expenses and Capital (OCC). Therefore, according to MEC it is the main tool to obtain resources and management by IFES.

\section{Final Considerations}

The present study sought to analyze the static and intertemporal frontiers of Federal Higher Education Institutions (IFES) in Brazil, using DEA methodology (SBM) and dynamic DEA (DSBM) and applying a model that determined the maximum educational output achieved by each institution investigated, since this output is a function of educational resources. Institutions were divided into two subsets in order to minimize heterogeneity in this sector. 
Results of static efficiency estimates for IFES in the first subset (group A) demonstrated a low efficient frontier, with around $54 \%$ of facilities positioned on the frontier throughout the period. Static efficiency estimates for group B institutions indicated an even lower frontier, with about $38 \%$ of institutions displaying efficiency over the entire period.

Dynamic frontier estimates of IFES in group A revealed that $64 \%$ were below the frontier and about $36 \%$ were above it. For IFES from group B, the frontier shift was far greater than in group B, with $76 \%$ of IFES on the efficient frontier and approximately $24 \%$ below it.

These findings show that including the carry-over variable (FTES) in the model resulted in productive gains on the frontier, indicating that the dynamic frontier is more robust than its static counterpart in capturing the change in productivity. Moreover, the impact of the frontier of group B IFES was more significant than for those in group $\mathrm{A}$.

Particularly, these results signalize that managers of public federal educational sector (Deans and Pro-deans of Planning), in order to obtain better levels of efficiency and consequently more resources to maintain their institutions, must provide inside their own institution mechanisms to supply enough subsidy to achieve better indicators, such as: resources, activity and teaching staff quality, research activity and higher education management. Only then, according to the present allocation of resources, possibly there will be better resources available for their institutions.

In conclusion, the comparison between results from the static and dynamic models can be summarized as follows: when compared to the dynamic model, the static model generally underestimates the efficiency of DMUs, which seems evident for DMUs exhibiting low efficiency indices, as was the case for IFES from group B. Thus, in the event of a set of observations in different time periods, it is advisable to use the dynamic DEA model, since it captures the deficits in models that measure evaluation in a single period of time.

\section{References}

BELLONI, J. A. Uma metodologia de avaliação da eficiência produtiva de universidades federais brasileiras. 2001. Tese (Doutorado em Engenharia de Produção) - Programa de Pós-Graduação em Engenharia de Produção, Universidade Federal de Santa Catarina, Florianópolis, 2001.

CHARNES, A.; COOPER, W. W. Measuring the efficiency and productivity of decision making units. European Journal of Operational Research, v. 3, n. 4, p. 339-338, 1979.

CHARNES, A.; COOPER, W.W.; RHODES, E. Measuring the effciency of DMUs. European Journal of Operational Research, v. 2, n. 6, p. 429.44, 1978. 
COOPER, W. W.; SEIFORD, L. M.; TONE, K. A comprehensive text with models, applications, references and DEA-Solver software. 2. ed. New York: Spring, 2007.

COSTA, E. M.; RAMOS, F. S.; SOUZA, H. R. Mensuração de eficiência produtiva das instituições federais de ensino superior IFES. In: STN/Esaf. (Org.). Finanças públicas - XV Prêmio do Tesouro Nacional: Homenagem a Joaquim Nabuco. Brasilia, DF: CODIN/STN, 2011.

DANTZING, G. B. Maximization of a linear function of variables subject to linear inequalities. In: KOOPMANS, T.C. (Ed.). Activity analysis of production and allocation. New York: Wiley, 1951.

DEBREU, G. The coefficient of resource utilization. Econometrica, v. 19, n. 3, p. 273-292. 1951.

FARE, R. et al. Productivity change in swedish hospitals: a Malmquist output index approach. 1994.

FARE, R.; GROSSKOPF, S. Intertemporal production frontiers: with dynamic DEA. Norwell: Kluwer, 1996.

FARRELL, M. The measurement of productive efficiency. Journal of the Royal Statistical Society, Series A, v. 120, n. 3, p. 253-290, 1957.

FLEGG, A. T. et al. Measuring the efficiency of British universities: a multi-period data envelopment analysis. Education Economics, v. 12, n. 3, p. 231-249, 2004.

FORSUND, F. R.; KALHAGEN, K, O. Efficiency and productivity of Norwegian Colleges. Oslo: Oslo University. Department of Economics, 1999. (Working Paper n. 11).

FORSUND, F. R.; LOVELL, C. A. K.; SCHMIDT, P. A survey of procution functions and their relationship to efficiency measurement. Journal of Econometrics, v. 13, n. 1, p. 5-25, 1980.

GEVA MAY, I. Higher education and attainment of policy goals: interpretations foreffciency indicators in Israel. Higher Education, v. 42, n. 3, p. 265-305, 2001.

GOTO, M.; NENOMOTO, J. Dynamic data envelopment analysis: modeling intertemporal behavior of a firm in the presence of productive inefficiencies. Economics Letters, v. 64, n. p. 51-56, 1999.

. Measurement of dynamic efficiency in production: an application of data envelopment analysis to Japanese electric utilities. Journal of Productivity Analysis, v. 19, n. 2-3, p.191-210, 2003.

INSTITUTO NACIONAL DE ESTUDOS E PESQUISAS EDUCACIONAIS. Censo da Educação Superior: 2004. Brasília, DF: Inep, 2009. Disponível em: <http://www.inep.gov.br>. Acesso em: 10 fev. 2010.

JOHNES, G.; JOHNES, J. International handbook on the economics of education. Cheltenham, UK; Northampton, MA, USA: Edward Elgar Publishing, 2004. cap. 16. p. 613-627.

JOUMADY, O.; RIS, C. Performance in European Higher Education: A Non-Parametric Production Frontier Approach. Journal of Education Economics, v. 13, n. 2, p. 189-205, 2005.

KLOPP, G. The analysis of the efficiency of production systems with multiple inputs and outputs. Chicago: University of Illinois at Chicago, Industrial and Systems Engineering College, 1985.

KOOPMANS, T. C. An analysis of production as an efficient combination of activities. In: KOOPMANS, T. C. (Ed.). Activity Analysis of Production and Allocation. Cowles Commission for Research in Economics, Monograph n. 13. New York: Johon Wiley and Sons, Inc., 1951. 
MALMQUIST, S. Index numbers and indifference surfaces. Trabajos de Estadística, n. 4, p. 209-42, 1953.

MCMILLAN, M.; DATTA, D. The relative efficiencies of Canadian universities: a DEA perspective. Canadian Public Policy, v. 24, n. 4, p. 485-511, 1988.

OLIVEIRA, C. E. M.; TURRIONI, J. B. Avaliação de desempenho de instituições federais de ensino superior através da Analise por Envoltória de Dados (DEA). 2006. Disponível em: <http:// www.iem.unifei.edu.br/turrioni/congressos/ENEGEP/2006/Avaliacao_de_desempenho_de instituicoes_federais_de_ensino_superior_atraves_da_analise_por_envoltoria_de_dados_(DEA).pdf $>$. Acesso em: 2 jun. 2009.

RHODES, E. L.; SOUTHWICK, L. Determinants of efficiency in public and private universities. Blomington: School of Environmental and Public Affairs. Indiana University, 1986. (Working Paper, n. 47405).

SENGUPTA, J. K. A dynamic efficiency model using data envelopment analysis. International Journal of Production Economics, v. 62, n. 3, p. 209-218, 1999.

. Nonparametric effciency analysis under uncertainty using data envelopment analysis. International Journal of Production Economics, v. 96, n. 1, p. 39-49, Jan. 2005. $\overline{665-671}, 1997$.

Persistence of dynamic effciency in Farrell models. Applied Economics, v. 29, n. 5, p.

SHEPHARD, R. Cost and production functions. Princeton, New Jersey: Princeton University, 1953.

SOUZA, H. R.; RAMOS. F. S. Performance evaluation in the public sector: an application of efficiency measures to Brazilian federal higher education institutions. Tenth World Productivity, p. 430-450, 1997.

TONE, K. A slacks based measure of efficiency in data envelopment analysis. Research report. Saitama University, Institute for Policy Science, Aug. 1997.

TONE, K.; TSUTSUI, M. A slacks-based measure of efficiency in data envelopment analysis. European Journal of Operational Research, v. 130, n. 3, p. 498-509, May 2001.

. Dynamic DEA: a slacks-based measure approach. Omega, v. 38, p. 145-156, 2010.

Recebido em: 01/06/2012.

Aceito em: 07/05/2013. 